\title{
Dehydrohalogenation of Alkyl Halides with Complementary Regioselectivity
}

Metal-Mediated Synthesis

Key words

cobalt catalysis

dehydrohalogenation

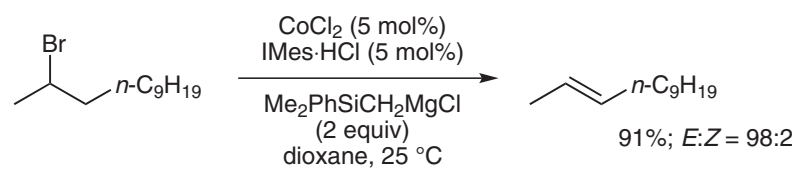

$\mathrm{CoCl}_{2}(5 \mathrm{~mol} \%)$

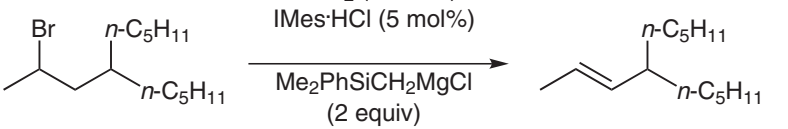

dioxane, $25^{\circ} \mathrm{C}$

Regioselectivity:<smiles>C=C(C=CCC)c1ccccc1</smiles>

$65 \%$

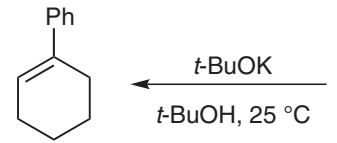

$68 \%$<smiles>C=C(CC(I)CC)c1ccccc1</smiles>

conditions

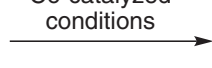<smiles>IC1CCCCC1c1ccccc1</smiles>
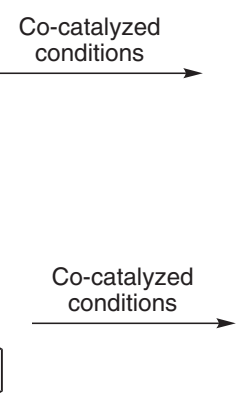

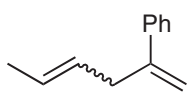

$49 \% ; E / Z=59: 41$

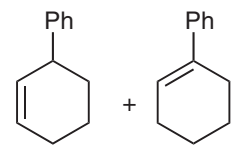

$67 \%$
Significance: This new Co-catalyzed dehydrohalogenation proceeds with excellent regioselectivity and mostly with good stereoselectivity. The Cocatalyzed dehydrohalogenation offers a complementary access to the introduction of double bonds, since it allows the formation of regioisomers that are not accessible via usual base-mediated elimination.
Comment: This method allows a novel, easy introduction of double bonds via dehydrohalogenation. The fact that regioisomers are obtained, which are different from those obtained with the common base-mediated elimination, makes it an important complementary synthetic tool.

SYNFACTS Contributors: Paul Knochel, Tobias Thaler 